\title{
Daytime F2-layer negative storm effect: what is the difference between storm-induced and Q-disturbance events?
}

\author{
A. V. Mikhailov, A. H. Depueva, and V. H. Depuev \\ Institute of Terrestrial Magnetism, Ionosphere and Radio Wave Propagation, Troitsk, Moscow Region 142190, Russia
}

Received: 19 April 2007 - Accepted: 21 June 2007 - Published: 30 July 2007

\begin{abstract}
Negative F2-layer storms related to geomagnetic activity and quiet-time disturbances (Q-disturbances) belong to different classes of events and exhibit different morphology. Mid-latitude daytime Q-disturbances, unlike the usual negative F2-layer storms, demonstrate $N m \mathrm{~F} 2$ and $h m \mathrm{~F} 2$ inphase variations. An analysis of Millstone Hill ISR observations for usual and Q-disturbances has shown the difference in the controlling aeronomic parameter variations for the two classes of events. The decrease in atomic oxygen concentration provides the main contribution to the $h m \mathrm{~F} 2$ decrease below the monthly median level during Q-disturbance events. Unlike the usual negative storms, the negative effect takes place in the whole topside ionosphere under Qdisturbance conditions. The difference is due to different effective plasma scale heights in the two cases. Clustering of the usual negative F2-layer disturbances around equinoxes and Q-disturbances around winter solstice, as well as different latitudinal variations for the occurrence of the two types of disturbances is due to their different formation mechanisms.
\end{abstract}

Keywords. Ionosphere (Ionosphere-atmosphere interactions; Ionospheric disturbances) - Atmospheric composition and structure (Thermosphere-composition and chemistry)

\section{Introduction}

There is a class of F2-layer disturbances which occur under quiet geomagnetic conditions (Q-disturbances), their magnitude being comparable to moderate F2-layer storm effects. The morphology of Q-disturbances and an interpretation of some of their features have been described by Mikhailov et al. (2004, 2007), Depueva et al. (2005). The morphological analysis of Q-disturbances has shown some differences

Correspondence to: A. V. Mikhailov

(avm71@orc.ru) with respect to the usual negative F2-layer storms related to geomagnetic activity. The differences are in: (a) $h m \mathrm{~F} 2$ variations; (b) $\mathrm{Ne}$ (h) distributions; (c) seasonal and latitudinal variations of the occurrence frequency. We are considering only daytime conditions, but a similar analysis, in principle, could be made for other periods of the day, when both the morphology and the formation mechanisms are different compared to the analyzed daytime hours.

According to ionosonde observations, $h m \mathrm{~F} 2$ do not exhibit any pronounced variations during Q-disturbance events which are close or even below monthly median values. Such $h m \mathrm{~F} 2$ behavior is different from the usual negative storm $h m \mathrm{~F} 2$ variations when the F2-layer maximum height always increases. For instance, the analysis by Papagiannis et al. (1975) of Millstone Hill ISR Ne(h) observations for the daytime period 10:00-16:00 LT has revealed a positive correlation between $h m \mathrm{~F} 2$ and the $K_{p}$ index $\left(0 \leq K_{p} \leq 6\right)$ for all seasons. It should be kept in mind that large $K_{p}$ values usually imply negative F2-layer storm conditions at middle latitudes. The $h m \mathrm{~F} 2$ increase during disturbed periods was also discussed by Zevakina (1971); Prölss (1995); Belehaki and Tsagouri (2002).

Another difference between the two classes of events is in the $\mathrm{Ne}(\mathrm{h})$ height distribution. In the case of the usual F2-layer storms related to geomagnetic activity, the negative storm effect is localized in the vicinity of the F2-layer maximum, but it changes for a positive effect in the topside F2region, above 400-600 km (Fatkullin and Legenjka, 1970). In the case of Q-disturbances, a negative effect takes place in the whole F2-region.

Further, the occurrence frequency of the usual mid-latitude negative F2-layer storms exhibits two maxima around the equinoxes, while negative Q-disturbances are the most frequent in winter (Fig. 1). This takes place at all levels of solar activity and in a wide range of latitudes.

And in the end, the latitudinal variations of the percent of time occupied by the disturbances are different for the

Published by Copernicus Publications on behalf of the European Geosciences Union. 

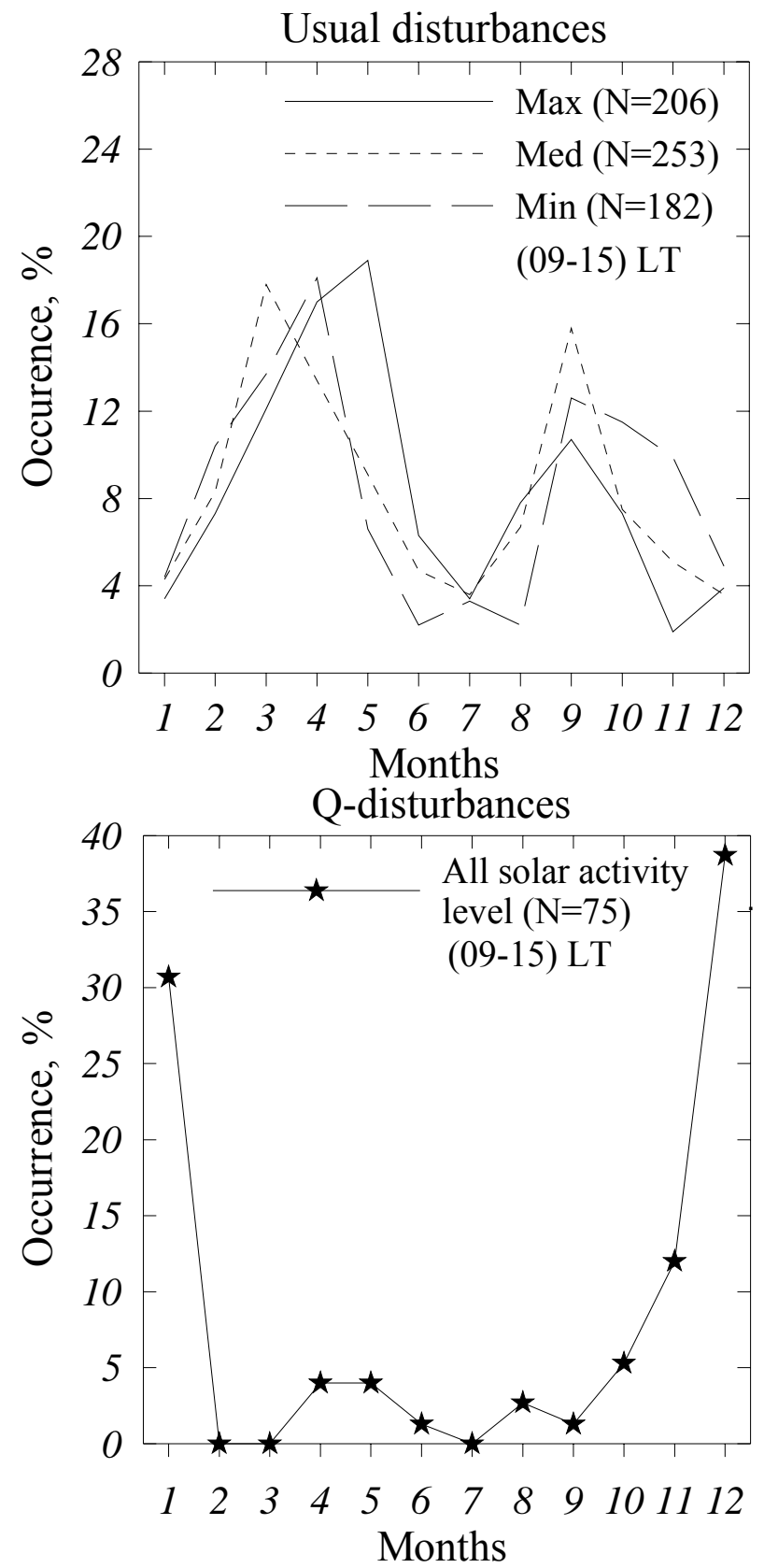

Fig. 1. Seasonal variations of the occurrence for the usual and Qdisturbances in the daytime LT sector. Due to the insufficient number of daytime negative Q-disturbances, all solar activity levels are put together; total number of events is given in parentheses.

two classes of events (Fig. 2). This parameter is related to the number or occurrence frequency of the disturbances. The usual negative disturbances demonstrate large and wellpronounced latitudinal variations, but very small latitudinal changes take place for Q-disturbances.

The details of the Q-disturbance extraction from the raw $f o \mathrm{~F} 2$ observations, which led to the results given in Figs. 1

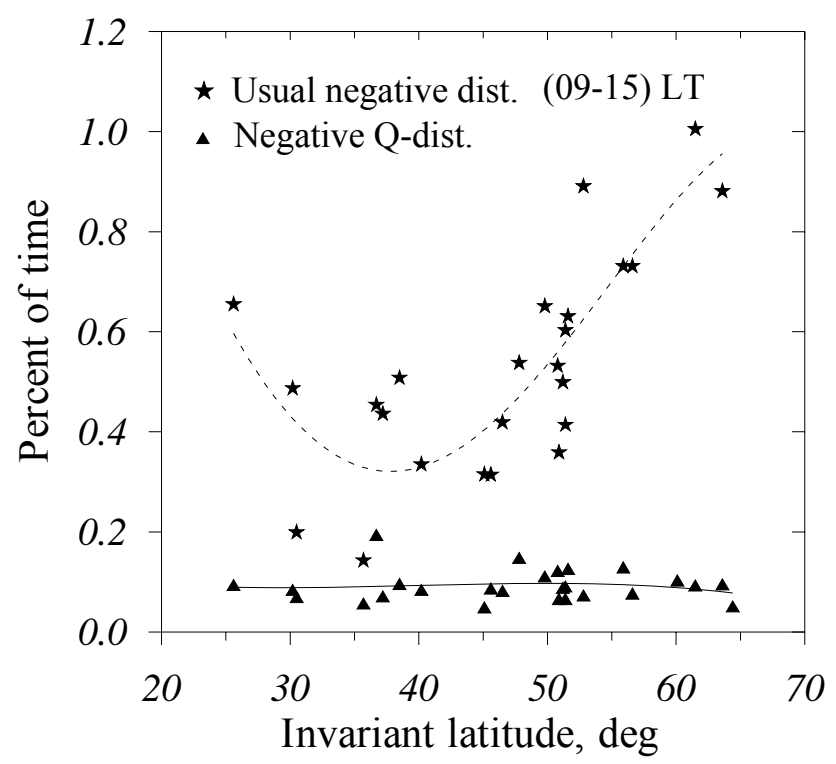

Fig. 2. Latitudinal variations of the percent of time occupied by the usual and Q-disturbances in the daytime LT sector. A polynomial approximation of the variations is given for the sake of obviousness. Note very small latitudinal changes for the Q-disturbances.

and 2, can be found in Mikhailov et al. (2004). But for the convenience of reading we repeat that all available observations over 26 ionosonde stations located in the Eurasian sector were used for the analysis. A 27-day $f_{o} \mathrm{~F} 2$ running median centered for the day in question was used as a reference level. Q-disturbances were referred to hourly $\left(\mathrm{N}_{m} \mathrm{~F} 2 / \mathrm{N}_{m} \mathrm{~F} 2\right.$ med -1$)$ deviations of more than $40 \%$ if all $3-\mathrm{h} a_{p}$ indices were $\leq 7$ for the 24 previous hours.

Obviously, these differences for the two types of events are due to different formation mechanisms of the two classes of disturbances (Mikhailov et al., 2007) and, in particular, to different variations of the main aeronomic parameters during such events. Therefore, the aim of the paper is to analyze $\mathrm{Ne}(\mathrm{h})$ variations in the cases of usual and quiet-time F2-layer negative disturbance events with the specification of aeronomic parameters responsible for the observed differences (the first two of the listed items), and to discuss the reasons for different seasonal and latitudinal variations of the occurrence frequency for the two classes of negative disturbances. Ground-based ionosonde, Millstone Hill and EISCAT ISR observations are used for the analysis.

\section{Ionosonde data analysis}

To obtain an idea of $h m \mathrm{~F} 2$ variations during negative Qdisturbances, some examples for mid-latitude stations are shown in Fig. 3 for the 6-8 January 1970 event. Note that unlike the usual negative F2-layer storm effect, here we have in-phase $N m \mathrm{~F} 2$ and $h m \mathrm{~F} 2$ variations, with $h m \mathrm{~F} 2$ being below 

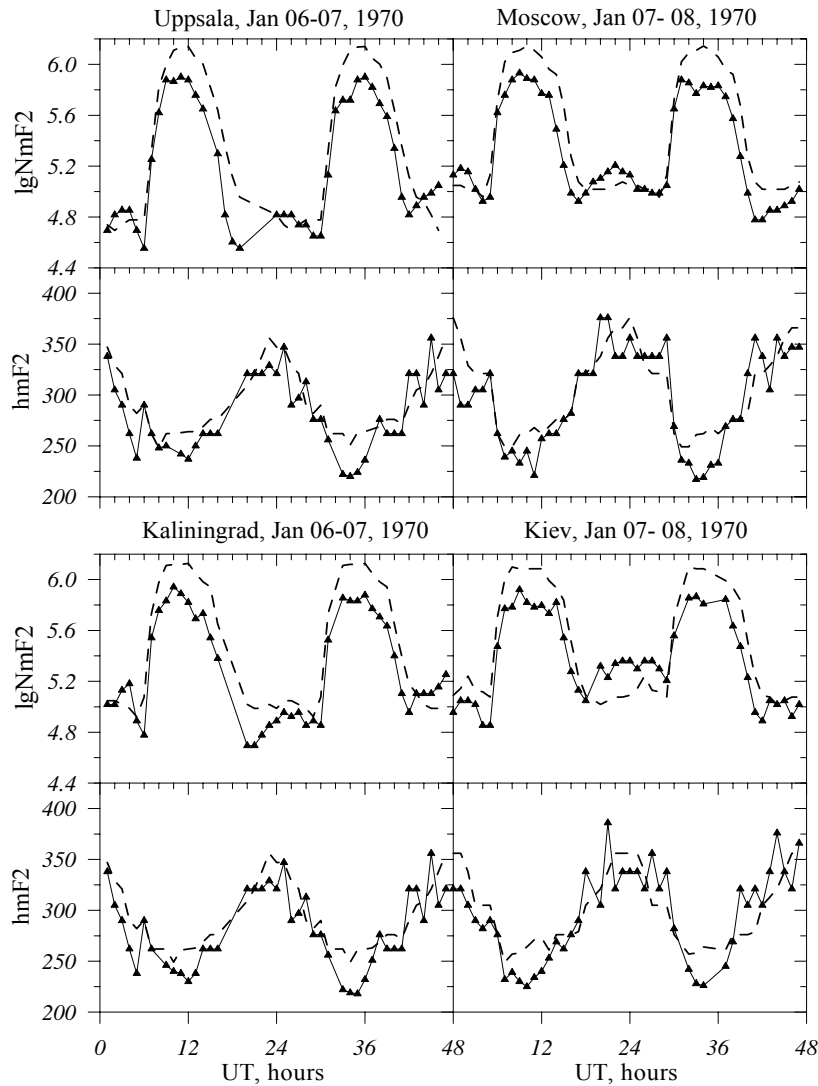

Fig. 3. Observed diurnal $N m \mathrm{~F} 2$ and $h m \mathrm{~F} 2$ variations at some European stations during the 6-8 January 1970 negative Q-disturbance event. Dashes - a 27-day running median. Note that daytime $h m \mathrm{~F} 2$ are below this median level.

the median values. A special analysis has been undertaken to check if this is a regular effect during daytime negative Qdisturbance events. Overall, 169 (station/date) daytime negative Q-disturbances have been considered using the Eurasian ionosonde network for the whole available period of observations (Table 1 in Mikhailov et al., 2004). The expression by Bradley and Dudeney (1973) was used to obtain $h m \mathrm{~F} 2$ from ionosonde observations. When data on foE were absent, the Simazaki (1955) expression was applied to obtain $h m \mathrm{~F} 2$ values. A 27-day running median centered for the day in question was used in the analysis. The advantages of using the 27day running median, rather than the usual monthly median, were discussed by Mikhailov et al. (2004). To decrease hourto-hour $h m \mathrm{~F} 2$ variations averaged over the (11:00-14:00) LT time interval $h m \mathrm{~F} 2$ values were used in the analysis.

The results of the statistical analysis gave us the average deviation $-13.4 \pm 9.67 \mathrm{~km}$ of $h m \mathrm{~F} 2$ from the median with the Student parameter $t=17.96$, i.e. the $h m \mathrm{~F} 2$ negative deviation from the median is significant at any confidence level. Thus, the statistical analysis has shown that the daytime negative F2-layer Q-disturbances are accompanied by a decrease in $h m \mathrm{~F} 2$.

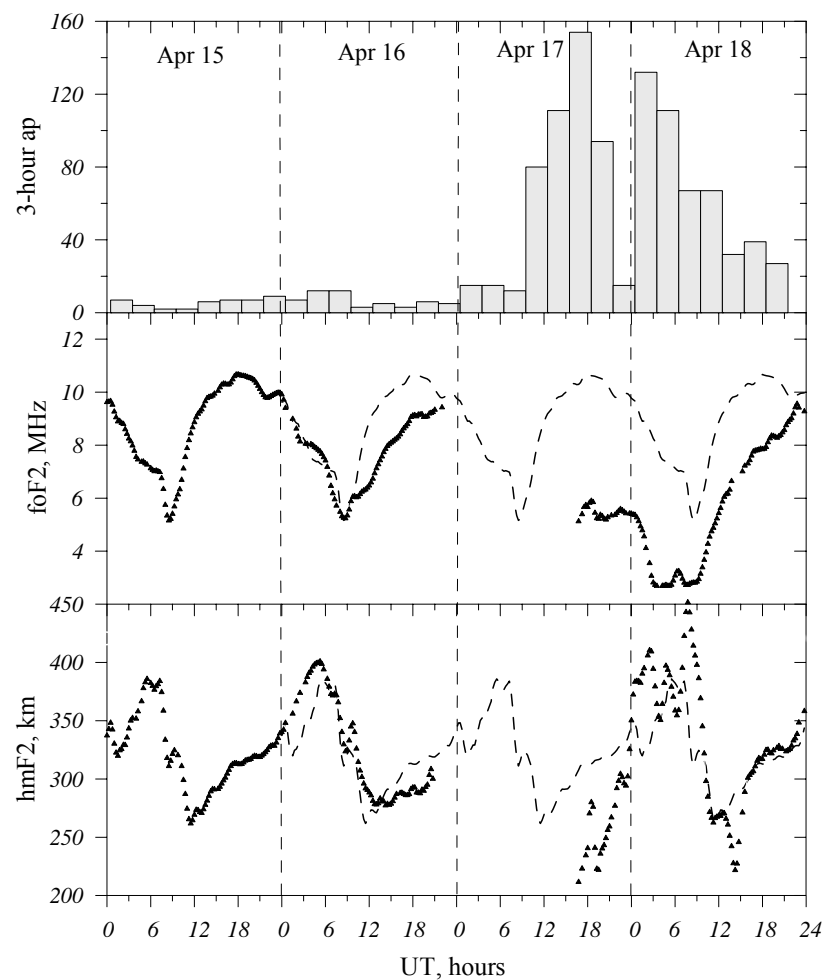

Fig. 4. Millstone Hill digisonde $f o \mathrm{~F} 2$ and $h m \mathrm{~F} 2$ diurnal variations for 15-18 April 2002. Note that $h m \mathrm{~F} 2$ are below median values for the day of Q-disturbance on 16 April. Low daytime hm values on 17-18 April correspond to the height of F1-layer maximum (Gconditions). Observed 3-h $a_{p}$ indices are given in the top panel.

\section{Interpretation}

One should consider in a comparison a daytime Qdisturbance event and a usual F2-layer negative storm effect related to an enhanced geomagnetic activity. The two cases should demonstrate similar negative deviations of $\delta N m \mathrm{~F} 2$ from their medians, while $\Delta h m \mathrm{~F} 2$ should have different signs. The period of 15-18 April 2002 with the Millstone Hill digisonde and the incoherent scatter radar (ISR) observations meets these requirements. The period may be considered as a lucky finding for the following reasons. The day of 16 April presents a good case of a daytime negative Qdisturbance event followed by a severe geomagnetic storm on 17-18 April, while 15 April practically coincides with the monthly median $f o F 2$ variations. Figure 4 presents Millstone Hill digisonde diurnal $f o \mathrm{~F} 2$ and $h m \mathrm{~F} 2$ variations along with 3-h $a_{p}$ indices for the period in question. The geomagnetic activity has decreased on 18 April and $\delta f o \mathrm{~F} 2$ deviations from the monthly median have become comparable for the two dates 16 April and 18 April during daytime (LT=UT-5) hours. The $\mathrm{Ne}(\mathrm{h})$ maximum heights are seen to be very low during the noon hours, both on 17 April and 18 April (see also Fig. 5 with ISR observations). This may be attributed to 


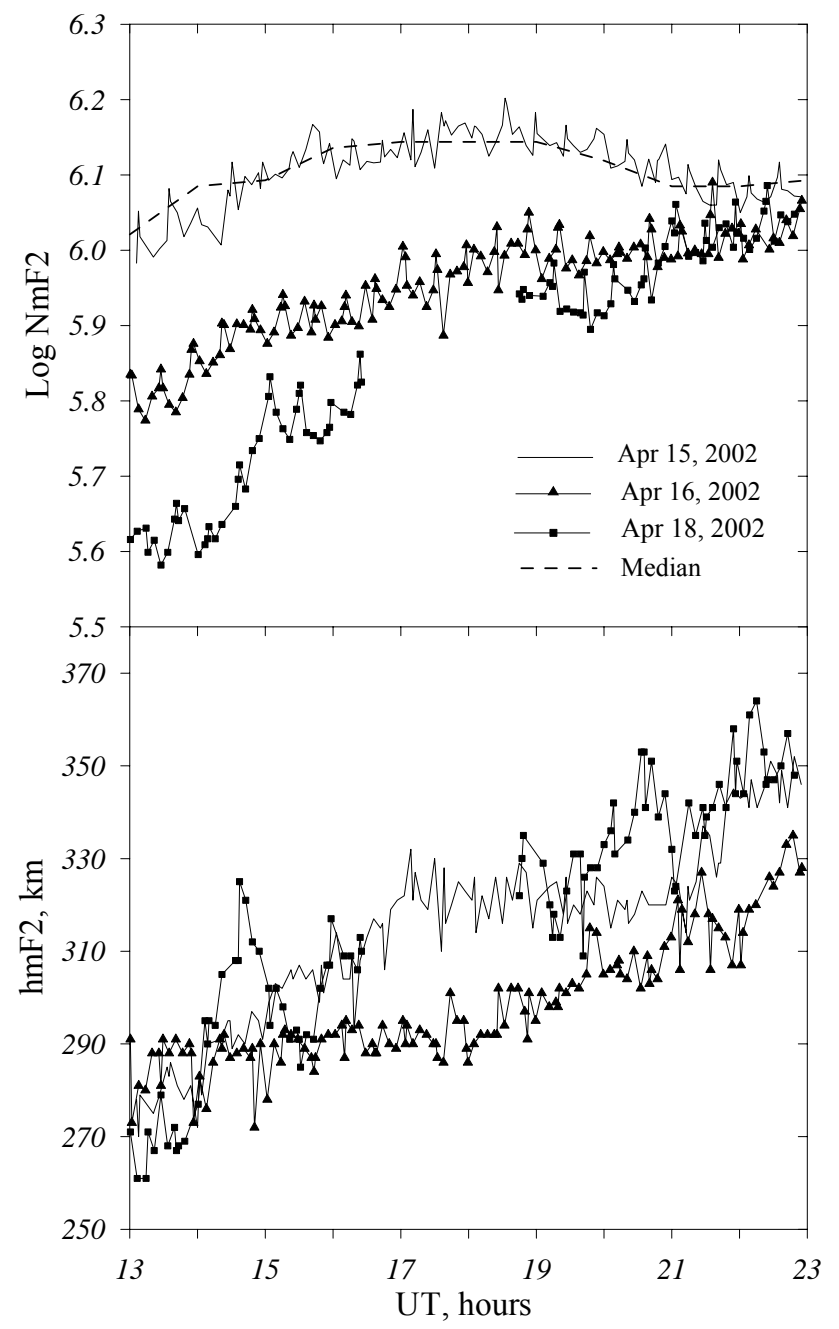

Fig. 5. Millstone Hill ISR observations of $N m \mathrm{~F} 2$ and $h m \mathrm{~F} 2$ diurnal variations for the negative Q-disturbance of 16 April 2002, a usual negative storm day of 18 April 2002, and a reference day of 15 April 2002 , which coincides with the monthly median. Note that $h m \mathrm{~F} 2$ are lower than the reference values for the Q-disturbance day and $h m \mathrm{~F} 2$ are higher than the reference level for the disturbed day of 18 April 2002.

G-conditions - the daytime phenomenon taking place during severe F2-layer storms, but we are interested in the 18:0021:00 UT period. This period falls on the recovery phase of the storm when $h m \mathrm{~F} 2$ values on 18 April have returned to the median level, according to the digisonde observations, while $h m \mathrm{~F} 2$ were lower than median values for the corresponding hours of 16 April (Fig. 4, bottom panel). The $\delta f o \mathrm{~F} 2$ deviations are comparable for the two dates during the afternoon hours.

Millstone Hill ISR provides the necessary daytime observations for 15-16 April, but on 18 April the observations are available only from 18:45 UT. The observed $N m \mathrm{~F} 2$ and $h m \mathrm{~F} 2$ variations are shown in Fig. 5 along with the $N m \mathrm{~F} 2$ monthly median obtained from the digisonde data. Unlike digisonde observations (Fig. 4), the ISR data provide the required difference in $h m \mathrm{~F} 2$ variations, with $h m \mathrm{~F} 2$ being higher than the median on 18 April and lower than the median on 16 April (Fig. 5, bottom panel). Obviously, the digisonde fails to interpret correctly the $h m \mathrm{~F} 2$ variations during G-conditions and it gives the height of F1-layer maximum rather than F2, while the ISR data show the expected increase in $h m \mathrm{~F} 2$. These ISR observations were used to reveal the reason for the difference in $h m \mathrm{~F} 2$ variations during the two classes of F2-layer disturbance events.

The self-consistent approach to the $\mathrm{N}_{e}(\mathrm{~h})$ modelling at F2region heights proposed by Mikhailov and Schlegel (1997), with the latest modifications by Mikhailov and Lilensten (2004), has been used to find the thermospheric neutral composition $\left([\mathrm{O}],\left[\mathrm{O}_{2}\right]\right.$, and $\left.\left[\mathrm{N}_{2}\right]\right)$, temperature $\mathrm{T}_{n}(\mathrm{~h})$, vertical plasma drift $W$ related to the neutral thermospheric winds and electric fields, as well as the total solar EUV flux with $\lambda<1050 \AA$. The details of the method may be found in the above-indicated references, so that only the main idea is sketched here. The standard set of ISR observations: electron density $\mathrm{Ne}(\mathrm{h})$, electron $T_{e}(\mathrm{~h})$ and ion $T_{i}(\mathrm{~h})$ temperature, as well as plasma velocity $\mathrm{VO}(\mathrm{h})$ vertical profiles - is the initial input information. All of these observed parameters enter the continuity equations for the main ionospheric ions in the F2-region. By fitting the calculated $\mathrm{Ne}(\mathrm{h})$ profile to the experimental one, a self-consistent set of the main aeronomic parameters responsible for the observed $\mathrm{Ne}(\mathrm{h})$ distribution can be found. The experimental profiles observed over some period (usually $1-2 \mathrm{~h}$ ) are specially processed before being used in the calculations. The results of the aeronomic parameters retrieval are given in Table 1 for the three dates and close UT time intervals.

Table 1 shows that $[\mathrm{O}], \beta=\gamma_{1}\left[\mathrm{~N}_{2}\right]+\gamma_{2}\left[\mathrm{O}_{2}\right]$, Tex, and $W$ variations are different for the 15 April/16 April and 15 April/18 April cases; the differences are given in Table 2.

A contribution of the main aeronomic parameters to $h m \mathrm{~F} 2$ variations can be estimated from the approximate expression by Ivanov-Kholodny and Mikhailov (1986) for an isothermal atmosphere:

$h_{m} \propto \frac{2.3 H}{3}\left\{\log [O]+\log \beta+\log \left(\frac{H^{2}}{0.54 d}\right)\right\}+c W$,

where $H=k T_{n} / \mathrm{mg}$ - atomic oxygen scale height, [O] and $\beta$ are given at a fixed height, say $300 \mathrm{~km}, W$ (in $\mathrm{m} / \mathrm{s}$ ) - vertical plasma drift velocity, $c$ is a coefficient close to unity, $d=1.38 \times 10^{19} \times\left(T_{n} / 1000\right)^{0.5}$ is a coefficient in the expression for the ambipolar diffusion coefficient $D=d /[\mathrm{O}]$.

It is seen from Eq. (1) and Table 2 that $\Delta \log [\mathrm{O}], \Delta \log \beta$, $\Delta \mathrm{Tex}$, and $\Delta W$ being of one sign, work in one direction, decreasing $h m \mathrm{~F} 2$ in the case of the Q-disturbance, but atomic oxygen provides the main contribution. Neutral temperatures Tex, according to our calculations and Millstone Hill estimates, are also lower on 16 April compared to 15 April 
Table 1. Calculated aeronomic parameters at $300 \mathrm{~km}$ for 15, 16, 18 April 2002. Italic - Millstone Hill Tex estimates.

\begin{tabular}{llllllll}
\hline Date & $\begin{array}{l}\mathrm{UT} \\
\text { (hour) }\end{array}$ & $\begin{array}{l}\mathrm{Tex} \\
(\mathrm{K})\end{array}$ & $\begin{array}{l}\log [\mathrm{O}]_{300} \\
\left(\mathrm{~cm}^{-3}\right)\end{array}$ & $\begin{array}{l}\log \left[\mathrm{O}_{2}\right]_{300} \\
\left(\mathrm{~cm}^{-3}\right)\end{array}$ & $\begin{array}{l}\log \left[\mathrm{N}_{2}\right]_{300} \\
\left(\mathrm{~cm}^{-3}\right)\end{array}$ & $\begin{array}{l}\log \beta_{300} \\
\left(\mathrm{~s}^{-1}\right)\end{array}$ & $\begin{array}{l}W \\
(\mathrm{~m} / \mathrm{s})\end{array}$ \\
\hline 15 April & $1830-1930$ & 14531460 & 8.796 & 6.857 & 8.319 & -3.575 & 0.0 \\
16 April & $1830-1930$ & 14171420 & 8.600 & 6.776 & 8.256 & -3.680 & -2.8 \\
18 April & $2000-2100$ & 14661480 & 8.853 & 7.109 & 8.411 & -3.428 & +8.8 \\
\hline
\end{tabular}

Table 2. Variations of aeronomic parameters for the two pairs of dates.

\begin{tabular}{lllll}
\hline Dates & $\Delta \mathrm{Tex}$ & $\Delta \log [\mathrm{O}]_{300}$ & $\Delta \log \beta_{300}$ & $\Delta W$ \\
\hline 16/15 April 2002 & -36 & -0.196 & -0.105 & -2.8 \\
18/15 April 2002 & 13 & 0.06 & 0.147 & 8.8 \\
\hline
\end{tabular}

and this also decreases $h m \mathrm{~F} 2$ (Eq. 1). Finally, the vertical plasma drift $W$ is negative (northward thermospheric wind) on 16 April and this also decreases $h m \mathrm{~F} 2$. Therefore, in the case of a negative Q-disturbance on 16 April, four controlling parameters $-[\mathrm{O}], \beta$, Tex and $W$ work in one direction, decreasing $h m \mathrm{~F} 2$.

The decrease in $\beta$ on 16 April with respect to the 15 April results from a lower concentration of molecule species $\mathrm{N}_{2}$ and $\mathrm{O}_{2}$ due to lower neutral temperature (Table 2), while low $[\mathrm{O}]$ during Q-disturbance events is mainly due to vertical gas motion (Mikhailov et al., 2007). Although the role of vertical plasma drift $W$ related mainly to thermospheric winds is known to be very essential in $h m \mathrm{~F} 2$ variations, the calculated $W$ is small (Table 1), varying around the zero level and does not contribute much to the $h m \mathrm{~F} 2$ variations. But it is seen as a tendency for $W$ to be negative (poleward $V n x$ ) under the Q-disturbance on 16 April and positive (equatorward $V n x$ ) during the usual negative F2-layer storm event on 18 April.

On the disturbed day of 18 April the observed $h m \mathrm{~F} 2$, on average, are higher than on 15 April (Fig. 5). This is mainly due to larger $\beta$ and Tex, and to positive vertical drift $W$ (Table 2). It is interesting to note that, although both observed and calculated Tex are close for the two dates, the concentrations of $\mathrm{N}_{2}$ and $\mathrm{O}_{2}$ are larger on 18 April compared to 15 April, while the atomic oxygen variations are small (Tables 1 and 2). Obviously, this is the result of the previous severe geomagnetic storm and strong upwelling of neutral gas enriching the thermosphere with molecular species and decreasing the [O] abundance (e.g. Rishbeth and Müller-Wodarg, 1999).

Cases of more pronounced $h m \mathrm{~F} 2$ variations due to changes in neutral temperature, composition and winds during the usual negative F2-layer storms can be found in Millstone Hill ISR observations. For instance, $N m \mathrm{~F} 2$ and $h m \mathrm{~F} 2$ variations for the storm event on 22 March $1990\left(\mathrm{~F}_{10.7}=244.7 / 229.3\right.$;

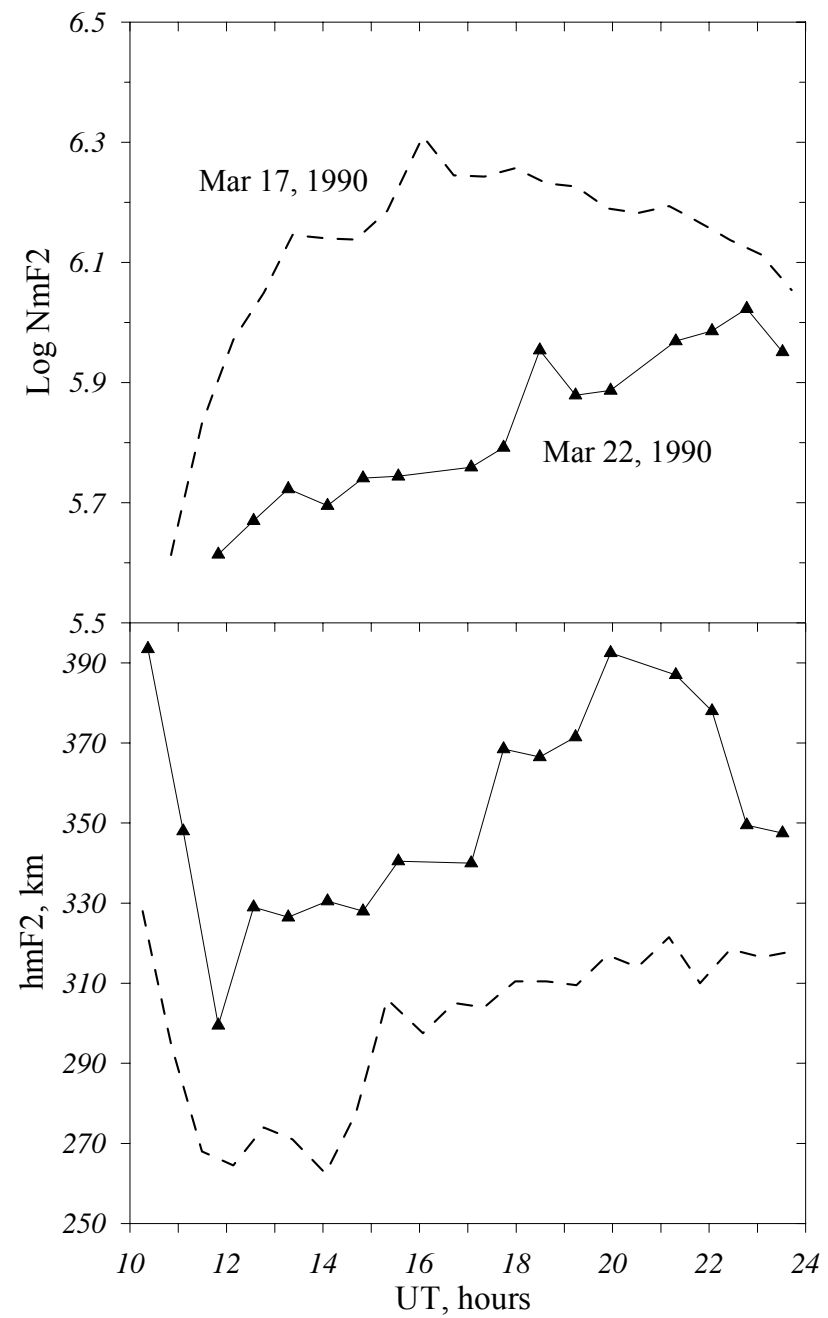

Fig. 6. A pronounced negative F2-layer storm event observed at Millstone Hill on 22 March 1990; a reference quiet day of 17 March 1990 is given for a comparison. Note that disturbed $h m \mathrm{~F} 2$ are much higher than the reference ones for all daytime hours.

$a_{p}=28 / 76$ for current and previous days), with the reference day of 17 March $1990\left(\mathrm{~F}_{10.7}=183.8 / 166.0 ; a_{p}=3 / 7\right)$, are shown in Fig. 6. This is a typical moderate negative F2-layer storm with a $60-\mathrm{km}$ difference in $h m \mathrm{~F} 2$ and a 2.5 times difference in $N m \mathrm{~F} 2$ for the noon hours between quiet 
Table 3. Calculated aeronomic parameters at $300 \mathrm{~km}$ for 17 March and 22 March 1990.

\begin{tabular}{llllllll}
\hline Date & $\begin{array}{l}\text { UT } \\
\text { (hour) }\end{array}$ & $\begin{array}{l}\text { Tex } \\
(\mathrm{K})\end{array}$ & $\begin{array}{l}\log [\mathrm{O}]_{300} \\
\left(\mathrm{~cm}^{-3}\right)\end{array}$ & $\begin{array}{l}\mathrm{Log}\left[\mathrm{O}_{2}\right]_{300} \\
\left(\mathrm{~cm}^{-3}\right)\end{array}$ & $\begin{array}{l}\log \left[\mathrm{N}_{2}\right]_{300} \\
\left(\mathrm{~cm}^{-3}\right)\end{array}$ & $\begin{array}{l}\log \beta_{300} \\
\left(\mathrm{~s}^{-1}\right)\end{array}$ & $\begin{array}{l}W \\
(\mathrm{~m} / \mathrm{s})\end{array}$ \\
\hline 17 March & $1630-1930$ & 1363 & 9.013 & 6.597 & 8.382 & -3.298 & -7.8 \\
22 March & $1700-2000$ & 1630 & 8.902 & 7.042 & 8.634 & -3.013 & +5.7 \\
\hline
\end{tabular}

and disturbed days. The retrieved aeronomic parameters are given in Table 3 for the two days in question. In this case a three-hour time interval was used for calculations, due to rare ISR observations (Fig. 6).

On the whole, the variations of aeronomic parameters are similar to the 15/18 April 2002 case, but in the case of 17/22 March 1990 they are more pronounced. The major reason for the $h m \mathrm{~F} 2$ increase is larger Tex, $\beta$, and $W$ values on 22 March. Unlike the previous case, the atomic oxygen concentration has decreased at F2-layer heights on 22 March despite high neutral temperature Tex. As was mentioned earlier, this is the result of strong neutral gas upwelling, leading to the impoverishment of the thermosphere with atomic oxygen. In both cases the vertical drift $W$ is positive on the disturbed day, implying the equatorward meridional thermospheric wind. This is in line with the present day understanding of the thermosphere disturbances resulting from an enhanced geomagnetic activity (Prölss, 1995; Fuller-Rowell et al., 1996; Rishbeth, 1998, and references therein).

The difference in $h m \mathrm{~F} 2$ variations during the usual and Q-disturbance events is due to a different state of the thermosphere in these cases. Negative Q-disturbances occur under a so-called ground state of the thermosphere (Mikhailov et al., 2007), which corresponds to a very low level of geomagnetic activity with an unconstrained solar-driven thermospheric circulation characterized during daytime by a poleward wind and relatively low atomic oxygen concentrations at middle and sub-auroral latitudes. Very low geomagnetic activity results in low neutral temperature Tex and, therefore, in low $\beta=\gamma_{1}\left[\mathrm{~N}_{2}\right]+\gamma_{2}\left[\mathrm{O}_{2}\right]$ (due to low $\left[\mathrm{O}_{2}\right]$ and $\left[\mathrm{N}_{2}\right]$ ) at $\mathrm{F} 2-$ region heights. Thus, all controlling aeronomic parameters work in one direction, decreasing $h m \mathrm{~F} 2$ (see Eq. 1).

The situation is inversed under elevated geomagnetic activity. The increase in neutral temperature results in a $\beta$ increase in the F2-region - both factors leading to the $h m \mathrm{~F} 2$ increase (see Eq. 1). An additional contribution to the $h m \mathrm{~F} 2$ increase provides positive vertical plasma drift resulting from the equatorward thermospheric wind. Depending on the intensity of the high-latitude heating, the normal solar-driven poleward (during daytime) thermospheric circulation may be inverted or only damped - in both cases $\Delta W>0$ is increasing $h m \mathrm{~F} 2$ with respect to quiet-time values. The thermosphere atomic oxygen abundance decreases due to the neutral gas upwelling; this decrease is partly compensated by the increase in neutral temperature. The two competing processes result in small [O] variations at F2-layer heights (Tables 2 and 3 ); therefore, the contribution of atomic oxygen variations to $\Delta h m \mathrm{~F} 2$ is not large.

Another earlier mentioned difference between negative Q-disturbances and the usual negative storm effects is in the $\mathrm{Ne}(\mathrm{h})$ height distribution. The smoothed $\mathrm{Ne}(\mathrm{h})$ profiles observed at Millstone Hill are shown in Fig. 7. The Qdisturbance $\mathrm{Ne}(\mathrm{h})$ profile on 16 April exhibits the effective plasma scale height close to that one for the reference day of 15 April 2002. Therefore, the negative disturbance effect takes place in the whole topside ionosphere. In the case of the usual negative storm effect, the $\mathrm{Ne}(\mathrm{h})$ is much broader (especially in the case of $22 \mathrm{March}$ ), and the negative effect is localized around the layer maximum, changing for the positive effect above $500-600 \mathrm{~km}$. Obviously, the difference is mainly due to different plasma temperatures for the dates in question. The plasma scale height is given by the expression

$H_{p}^{-1}=\frac{m_{i} g}{k\left(T_{e}+T_{i}\right)}+\frac{1}{T_{e}+T_{i}} \frac{d\left(T_{e}+T_{i}\right)}{d h}$,

where all symbols are standard. The observed at $500 \mathrm{~km}$ $\left(T_{e}+T_{i}\right), \mathrm{d}\left(T_{e}+T_{i}\right) / \mathrm{dh}$, as well as $H_{p}$ values, are given in Table 4 .

Calculated plasma scale heights for the dates of usual negative storm events are larger (as it is expected) than for the reference days, and this is mainly due to higher temperatures. The plasma scale height for 16 April 2002 is also larger than for 15 April due to higher $T_{e}$, but ion temperature, which is closely related to neutral temperature, is lower on 16 April. Therefore, the overall difference in $H_{p}$ between the two dates is not very large. On the other hand, it should be kept in mind that the effective scale height $\mathrm{Heff}=(-\mathrm{dlnNe} / \mathrm{dh})^{-1}$ bears the effect of plasmasphere-ionosphere fluxes and vertical plasma drifts (Ivanov-Kholodny and Mikhailov, 1986, and references therein). The upward flux from the F2-region during daytime hours and downward plasma drift due to the northward thermospheric wind both decrease Heff. Therefore, some differences between the calculated $H_{p}$ values, which correspond to the barometric height distribution of plasma, and the observed Heff (Fig. 7), may be attributed to the dynamical effects. In any event, the effective plasma scale height for the Q-disturbance event is close to Heff for the reference day, while they essentially differ in the case of the usual negative storm effect. 
Table 4. Observed at Millstone Hill plasma temperatures, their gradients and plasma scale heights at $500 \mathrm{~km}$ for quiet and disturbed days.

\begin{tabular}{llllll}
\hline Date & 15 April 2002 & 16 April 2002 & 18 April 2002 & 17 March 1990 & 22 March 1990 \\
\hline$T_{e}, \mathrm{~K}$ & 2325 & 2899 & 2681 & 2065 & 3337 \\
$T_{i}, \mathrm{~K}$ & 1550 & 1514 & 1586 & 1472 & 1644 \\
$\mathrm{~d}\left(T_{e}+T_{i}\right) / \mathrm{dh}, \mathrm{K} / \mathrm{cm}$ & $4.85 \mathrm{e}-5$ & $4.49 \mathrm{e}-5$ & $3.05 \mathrm{e}-5$ & $6.00 \mathrm{e}-5$ & $2.80 \mathrm{e}-5$ \\
$H_{p}, \mathrm{~km}$ & 184 & 213 & 222 & 159 & 262 \\
\hline
\end{tabular}

\section{Discussion}

Daytime negative F2-layer Q-disturbances is a special class of F2-layer perturbations with their own morphology and formation mechanisms (Mikhailov et al., 2007, and references therein). The in-phase $N m \mathrm{~F} 2$ and $h m \mathrm{~F} 2$ decrease is a distinctive feature of negative Q-disturbances. This is different from the usual negative F2-layer storm effect, when $h m \mathrm{~F} 2$ always increases mainly due to the enhanced neutral temperature and linear loss coefficient $\beta$ (Tables 1-3). Negative Q-disturbances occur under very low geomagnetic activity when the intensity of the auroral heating is minimal. Such conditions correspond to a ground state of the thermosphere with an unconstrained solar-driven thermospheric circulation (poleward neutral wind during daytime) and relatively low atomic oxygen concentrations at middle and sub-auroral latitudes. It follows from the model calculations by Rishbeth and Müller-Wodarg (1999), that low [O] may be related to a moderate upwelling of neutral gas in a wide range of latitudes (their Fig. 3). The results of our calculations (Table 1) are confirmed by GUVI/TIMED observations, which also show a low $[\mathrm{O}] /\left[\mathrm{N}_{2}\right]$ column ratio for the day of negative Q-disturbance on 16 April 2002 (Goncharenko et al., 2006). The ground state of the thermosphere with the northward meridional wind did take place on 16 April. According to Millstone Hill estimations, Vnx was northward until 21:00 UT (Goncharenko et al., 2006, their Fig. 17). Therefore, the decrease in the four controlling parameters, $[\mathrm{O}], \beta$, Tex, and $W$ (Table 2), provides the $h m \mathrm{~F} 2$ decrease during negative Q-disturbance events, with the main contribution belonging to the atomic oxygen variations.

In the case of the usual negative storm effect related to an enhanced geomagnetic activity three parameters, $\beta$, Tex, and $W$, always increase (Tables 1-3), thus providing the increase in $h m \mathrm{~F} 2$. Unlike the Q-disturbance case, the contribution of atomic oxygen variations to $\Delta h m \mathrm{~F} 2$ is small or even negative, as in the case of 17/22 March 1990 (Table 3). These changes in the aeronomic parameters are the result of the auroral heating and the interaction between the background (solar-driven) and storm-induced thermospheric circulations (Duncan, 1969; Prölss, 1995; Fuller-Rowell et al., 1996; Rishbeth, 1998; Rishbeth and Müller-Wodarg, 1999, and references therein).

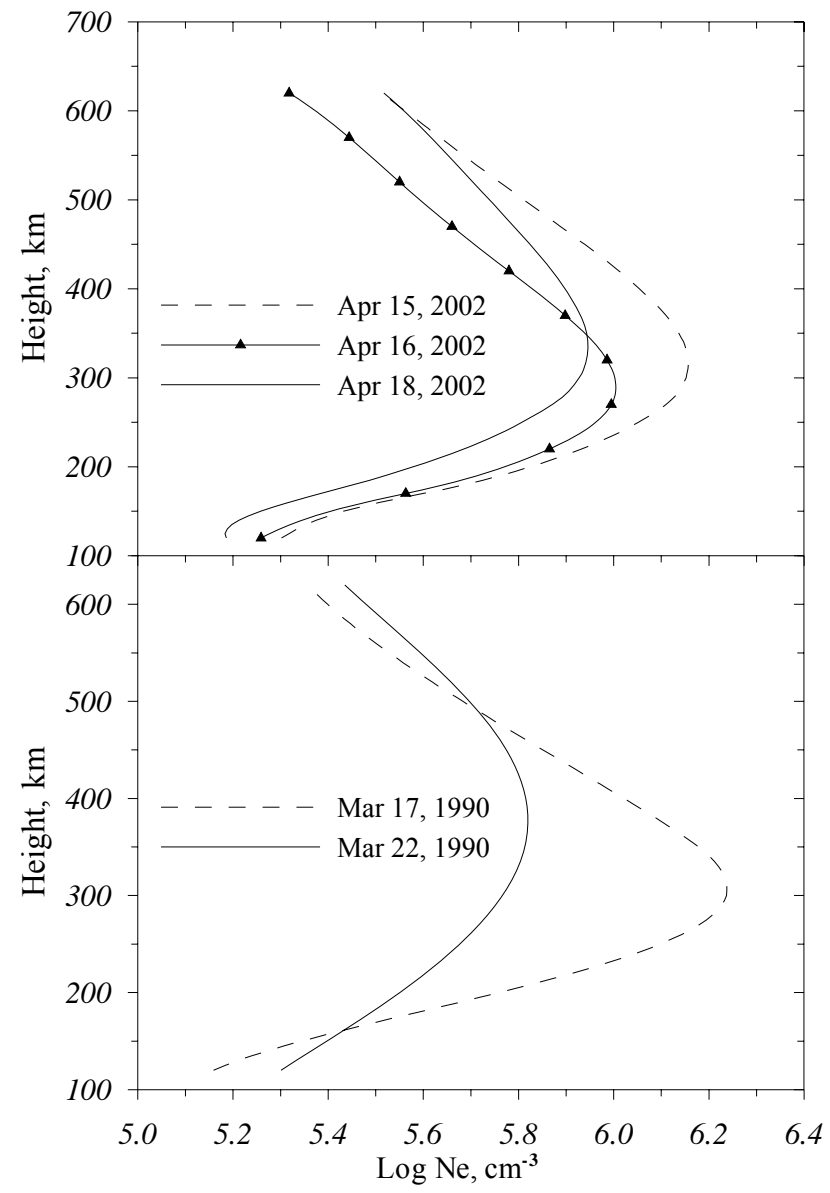

Fig. 7. Observed smoothed $\mathrm{Ne}(\mathrm{h})$ profiles for the periods given in Tables 1 and 3. The effective scale height of $\mathrm{Ne}(\mathrm{h})$ distribution for 16 April 2002 is close to $H_{\text {eff }}$ for the reference day of 15 April 2002 and the negative effect takes place in the whole F2-region for the Qdisturbance event. In the case of the usual negative disturbances on 18 April 2002 and 22 March 1990 the negative effect is localized around the F2-layer maximum.

During severe geomagnetic storms G-conditions $(N m \mathrm{~F} 2<N m \mathrm{~F} 1)$ may take place at middle latitudes. In this case a ground-based ionosonde registers the height of the F1-layer (Fig. 4), which erroneously may be taken for the $h m \mathrm{~F} 2$. Actually, $h m \mathrm{~F} 2$ increases under such conditions (Fig. 5, bottom panel), but a similar effect with decreasing 

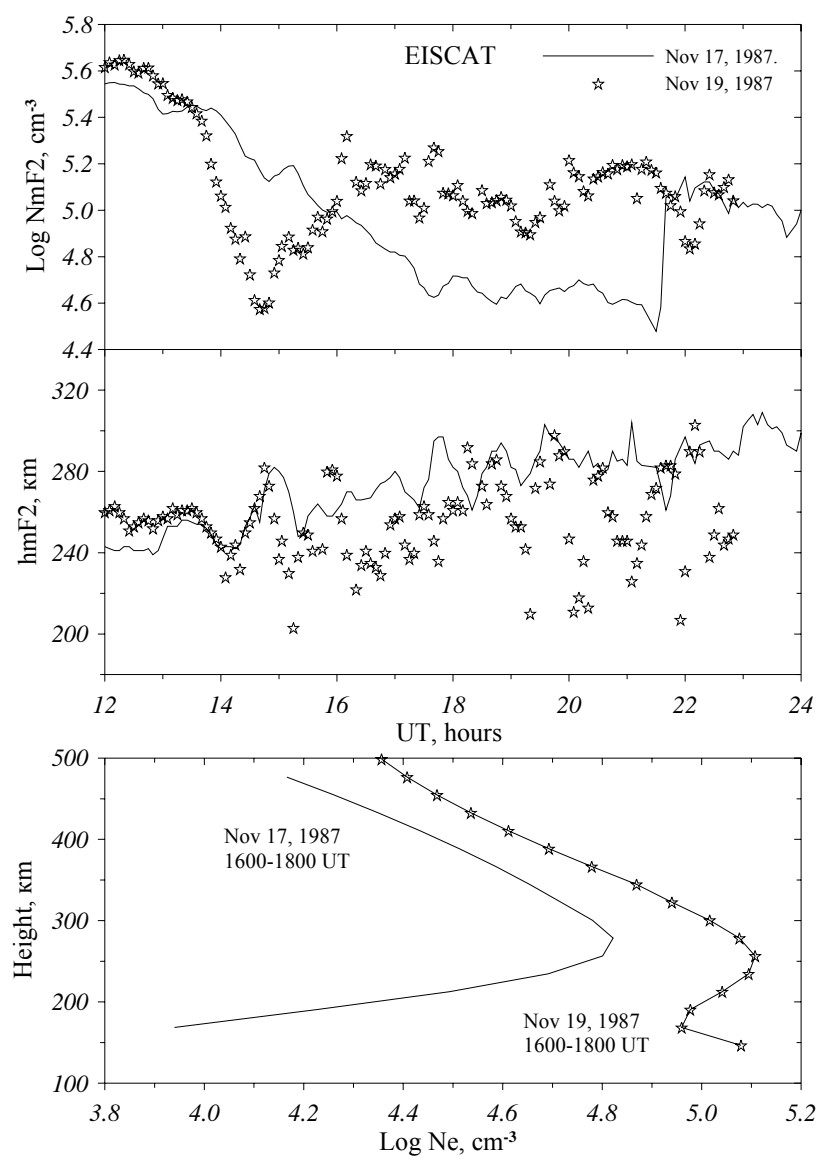

Fig. 8. The effect of electron precipitation decreasing $h m \mathrm{~F} 2$ observed with EISCAT for a moderately disturbed day 19 November 1987. A reference quiet day, 17 November 1987, is shown for a comparison. An intensive ionization in the lower part of the F2region shifts the $\mathrm{Ne}(\mathrm{h})$ maximum to lower heights.

$h m \mathrm{~F} 2$ can be observed in the high-latitude F2-layer during particle precipitation events. Observed with EISCAT $N m \mathrm{~F} 2$ and $h m \mathrm{~F} 2$ diurnal variations along with $\mathrm{Ne}(\mathrm{h})$ profiles are shown in Fig. 8 for a quiet 17 November $1987\left(a_{p}=3\right)$ and a moderately disturbed 19 November $1987\left(a_{p}=12\right)$. Electric fields $E \approx 20-40 \mathrm{mV} / \mathrm{m}$ and an intensive electron precipitation took place on 19 November while both characteristics were small on 17 November. Observed $N m \mathrm{~F} 2$ are higher and $h m \mathrm{~F} 2$ are lower on 19 November for the period 16:00-22:00 UT when an intensive electron precipitation is expected. Large scatter in the observed $h m \mathrm{~F} 2$ is seen on 19 November and obviously this is due to a varying precipitation intensity. Median $\mathrm{Ne}(\mathrm{h})$ profiles found over the 16:00-18:00 UT period are given in Fig. 8 for the two days in question. Strong precipitation results in the increase in electron concentration (especially in the lower F-region), as well as in the decrease in $h m F 2$. Strong plasma production at lower altitudes shifts $h m \mathrm{~F} 2$ to lower heights (e.g. Torr and Torr, 1969).
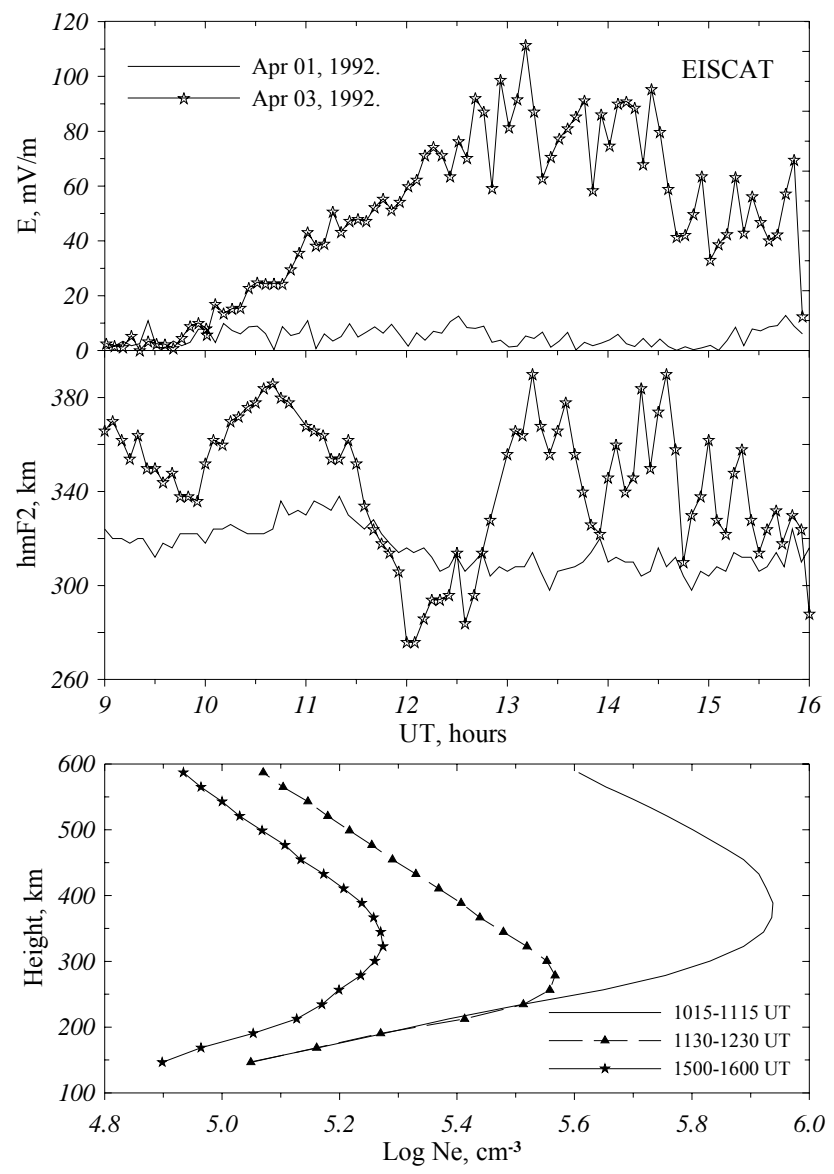

Fig. 9. The effect of a strong electric field (top panel) resulting in a large $h m \mathrm{~F} 2$ decrease at the initial phase of the storm observed with EISCAT on 3 April 1992. A quiet reference day, 1 April 1992, is given for a comparison. The $h m \mathrm{~F} 2$ decrease results from a strong decrease in the electron concentration above $240 \mathrm{~km}$ due to a horizontal plasma transfer under the $\boldsymbol{E} \times \boldsymbol{B}$ drift.

A decrease in $h m \mathrm{~F} 2$ during daytime storm events in the auroral F2-region may also result from strong electric fields. EISCAT observations on 3 April 1992 present such an example (Fig. 9), with 1 April being a reference day. A sharp increase in the electric field is accompanied by a large (about $100 \mathrm{~km}$ ) decrease in $h m \mathrm{~F} 2$ at the initial stage of the storm; such an effect is never observed at middle latitudes. Three median $\mathrm{Ne}(\mathrm{h})$ profiles calculated over 1-h intervals illustrate the effect (Fig. 9, bottom panel). A large decrease in electron concentration is seen in the topside around 12:00 UT while the $\mathrm{Ne}(\mathrm{h})$ profile coincides with the pre-storm one below $240 \mathrm{~km}$. Obviously, in this case one should expect the decrease in the effective $h m F 2$. The effect may be related to a strong horizontal westward plasma transfer. According to EISCAT observations, the westward $\boldsymbol{E} \times \boldsymbol{B}$ drift around 12:00 UT was $\sim 1 \mathrm{~km} / \mathrm{s}(E \sim 50 \mathrm{mV} / \mathrm{m}$, Fig. 9, top panel). Under this velocity and a characteristic (e-folding) time of $\sim 1.5 \mathrm{~h}$ for the daytime F2-layer maximum, plasma can be transferred over 9 local time zonal belts at the latitude of $70^{\circ}$. 
This corresponds to nighttime not sunlit conditions, with low $N m \mathrm{~F} 2$ values, as 3 April is close to the equinox. The coincidence of the two $\mathrm{Ne}(\mathrm{h})$ profiles below $240 \mathrm{~km}$ (Fig. 9, bottom panel) explicitly tells us that the thermospheric parameters have not been yet altered by this time. Neutral composition and temperature have become perturbed at the later stage of the storm and this (along with the electric field effect in $\beta$ increase) is manifested in the $\mathrm{Ne}(\mathrm{h})$ profile for 15:0016:00 UT.

In the end, let us consider the difference in the occurrence frequency for usual and Q-disturbance events (Figs. 1, 2). The usual negative F2-layer storm effect is known to be related to an enhanced geomagnetic activity followed by the perturbation in neutral composition, temperature and winds (e.g. Prölss, 1995). Running average $a_{p}$ indices exhibit a pronounced equinoctial maximum (e.g. Roosen, 1966). Therefore, the clustering of usual negative disturbances around equinoxes (Fig. 1, left panel) just reflects this experimental fact.

The situation with Q-disturbances is more complicated and related to the negative Q-disturbances formation mechanism (Mikhailov et al., 2007). Such disturbances occur under very quiet geomagnetic conditions corresponding to a ground state of the thermosphere with the poleward wind during daytime and a relatively low atomic oxygen concentration. The poleward wind is seasonally dependent, being the strongest in winter (Buonsanto and Witasse, 1999, their Fig. 5). This is partially due to the fact that Joule heating is minimal in winter when the ionization and conductivity levels are low, reinforcing the prevailing solar-driven circulation (Forbes et al., 1996; Fuller-Rowell et al., 1996). The poleward thermospheric wind produces in the F2-region a downward plasma drift decreasing $N m$ F2. This is the reason why the daytime negative Q-disturbances cluster around the winter solstice (Fig. 1, right panel). According to the model calculations by Rishbeth and Müller-Wodarg (1999, their Fig. 3), there is a moderate upwelling (about $0.5 \mathrm{~m} / \mathrm{s}$ ) in a wide range of latitudes around the noontime under quiet $\left(K_{p}=2+\right)$ conditions in December. Such upwelling is able to support the low background level of the atomic oxygen concentration. This relatively low atomic oxygen abundance is the main cause of negative Q-disturbances, as it was also stressed in this analysis (Table 2).

The difference in the formation mechanism of the two classes of disturbances explains different latitudinal variations of their occurrence frequency (Fig. 2). The daytime F2-layer negative storm effect is roughly proportional to the $\mathrm{O} / \mathrm{N}_{2}$ ratio (Prölss, 1980). Changes of this ratio are due to the $[\mathrm{O}]$ decrease and $\left[\mathrm{N}_{2}\right]$ increase, where the latter dominates. The ESRO-4 gas analyzer observations clearly demonstrate that with growing magnetic activity there is an increase in the amplitude and in the extension of the composition disturbance (Prölss, 1980, his Fig. 16). This is in line with the latitudinal dependence in Fig. 2 for the occurrence of usual negative disturbances.
The formation mechanism of daytime negative Qdisturbances implies the ground state of the thermosphere with a poleward thermospheric wind and low atomic oxygen concentration, the latter providing the main contribution (Mikhailov et al., 2007). According to the NRLMSISE00 model (Picone et al., 2002), the latitudinal variations of atomic oxygen at F2-region heights are very small (5-10\%), within the $\left(35-65^{\circ}\right)$ latitudinal interval under low geomagnetic activity in December (winter solstice). These small latitudinal variations are in line with the results of the model calculations by Rishbeth and Müller-Wodarg (1999, their Fig. 3), showing almost a constant moderate upwelling in a wide range of latitudes under daytime quiet conditions in December. The other parameter, the downward vertical plasma drift $W=V n x \operatorname{Sin} I \operatorname{Cos} I$, also does not change much with latitude. Although the $\operatorname{Sin} I \operatorname{Cos} I$ product decreases by a factor of 2 within the considered latitudinal range, according to the UARS observations, the northward wind $V n x$ increases with latitude during the December solstice under daytime quiet conditions (Fejer et al., 2000, their Fig. 1). Therefore, one should not expect pronounced latitudinal variations of $N m \mathrm{~F} 2$ for the conditions in question. The small changes in $\delta \mathrm{Nm}=\mathrm{Nm} / \mathrm{Nm}_{\text {med }}$ also imply small latitudinal variations in the $N m \mathrm{~F} 2$ median values. The analysis has shown small ( $<6 \%$ under solar maximum and $<20 \%$ under solar minimum) $N m \mathrm{~F} 2$ med variations over a wide range at middle latitudes for the noon hours in December. Small latitudinal variations of the Q-disturbance amplitude were discussed earlier by Mikhailov et al. (2004, their Fig. 9).

\section{Conclusions}

The results of our analysis may be summarized as follows:

1. Negative F2-layer storms related to geomagnetic activity and Q-disturbances belong to different classes of events and exhibit a different morphology with respect to: (a) $h m \mathrm{~F} 2$ variations; (b) $\mathrm{Ne}(\mathrm{h})$ distributions; (c) seasonal and latitudinal variations of the occurrence frequency.

2. In contrast to the usual negative storm effect when $h m \mathrm{~F} 2$ always increases, during Q-disturbance events $N m \mathrm{~F} 2$ and $h m \mathrm{~F} 2$ demonstrate in-phase variations with $h m \mathrm{~F} 2$ dropping below median values. The result was obtained over 169 cases of daytime negative Q-disturbances and statistically is significant. The analysis of Millstone Hill ISR observations for the day of negative Q-disturbance (16 April 2002) has shown that four controlling parameters, $[\mathrm{O}], \beta$, Tex, and $W$, work in one direction, decreasing $h m \mathrm{~F} 2$, with the atomic oxygen variations providing the main contribution. In the case of the usual negative disturbances, the increase in Tex, $\beta$, and $W$ provides the increase in $h m \mathrm{~F} 2$. The decrease of atomic oxygen abundance due to the neutral gas upwelling is 
partly compensated by the increase in neutral temperature. The two competing processes result in small [O] variations at F2-layer heights, therefore, the contribution of atomic oxygen variations to $\Delta h m \mathrm{~F} 2$ is not large under the usual negative storm conditions.

3. The difference in $h m \mathrm{~F} 2$ variations during the usual and Q-disturbance events is due to a different state of the thermosphere in these cases. Negative Q-disturbances occur under a so-called ground state of the thermosphere, which corresponds to a very low level of geomagnetic activity with relatively low neutral temperature, an unconstrained solar-driven thermospheric circulation characterized during the daytime by a poleward wind and relatively low atomic oxygen concentrations at middle and sub-auroral latitudes. Under elevated geomagnetic activity the situation is inversed; neutral temperature increases, the solar-driven poleward wind is damped or inverted (depending on the intensity of the high-latitude heating), the thermospheric atomic oxygen abundance is decreased. In both cases [O] decreases, but the mechanisms of this decrease are different.

4. Unlike middle latitudes in the auroral daytime F2-layer, $h m \mathrm{~F} 2$ may drop below the quiet time reference level during geomagnetically disturbed periods. But this is due either to particle precipitation or strong electric fields changing the $\mathrm{Ne}(\mathrm{h})$ profile.

5. Under Q-disturbance events the negative effect takes place in the whole topside ionosphere, while in the case of the usual negative storms the negative effect is localized in the vicinity of the layer maximum, changing for the positive effect above $500-600 \mathrm{~km}$. The difference is mainly due to different plasma temperatures for the two cases. The effective plasma scale height during the Q-disturbance event is close to Heff for the reference day, while they essentially differ in the case of the usual negative storm events.

6. Clustering of the usual negative F2-layer disturbances around equinoxes and Q-disturbances, around winter solstice is due to different mechanisms of their formation. The usual negative F2-layer storm effect is known to be related to enhanced geomagnetic activity (e.g. Prölss, 1995), which exhibits the pronounced equinoctial maxima (e.g. Roosen, 1966). Q-disturbances occur under the ground state of the thermosphere with the poleward wind during daytime. The poleward wind is the strongest in winter due to the minimal Joule heating. This wind produces a downward plasma drift decreasing $N m \mathrm{~F} 2$. This is the reason why the daytime negative Q-disturbances cluster around the winter solstice.

7. The difference in the mechanisms for the two classes of disturbances also explains the different latitudinal varia- tions for their occurrence. The occurrence frequency of the usual negative daytime disturbances manifests the $\mathrm{O} / \mathrm{N}_{2}$ ratio variations. The amplitude and latitudinal extension of this ratio, according to the ESRO-4 gas analyzer observations (Prölss, 1980), demonstrate the same type of variations as the occurrence frequency. In the case of negative Q-disturbances the two parameters, [O] and $W=V n x \operatorname{Sin} I \operatorname{Cos} I$, responsible for their formation, do not change much with latitude. This explains small latitudinal variations for the occurrence of the daytime negative Q-disturbances.

Acknowledgements. This work was in part supported by the Russian Foundation for Basic Research under Grant 06-05-64227. The authors thank the Millstone Hill Group of the Massachusetts Institute of Technology, Westford; also the staff of EISCAT for running the radar and providing the data. The EISCAT Scientific Association is funded by scientific agencies of Finland (SA), France (CNRC), Germany (MPG), Japan (NIPR), Norway (NF), Sweden (NFR), and the United Kingdom (PPARC).

Topical Editor M. Pinnock thanks A. Danilov and another anonymous referee for their help in evaluating this paper.

\section{References}

Belehaki, A. and Tsagouri, I.: On the occurrence of storm-induced nighttime ionization enhancements at ionospheric middle latitudes, J. Geophys. Res., 107, 22-41, 2002.

Bradley, P. A. and Dudeney, J. R.: A simple model of the vertical distribution of electron concentration in the ionosphere, J. Atmos. Terr. Phys., 35, 2131-2146, 1973.

Buonsanto, M. J. and Witasse, O. G.: An updated climatology of thermospheric neutral winds and $\mathrm{F}$ region ion drifts above Millstone Hill, J. Geophys. Res., 104, 24 675-24 687, 1999.

Depueva, A. Kh., Mikhailov, A. V., and Depuev, V. Kh.: Quiet time F2-layer disturbances at geomagnetic equator, Int. J. Geomag. Aeronom., 1-11, GI3001, doi:10.1029/2004GI000071, 2005.

Duncan, R. A.: F-region seasonal and magnetic-storm behavior, J. Atmos. Terr. Phys., 31, 59-70, 1969.

Fatkullin, M. N. and Legenjka, A. D.: An altitude distribution of storm effect in the outer ionosphere, Geomag. Aeronom. (in Russian), 10, 435-442, 1970.

Fejer, B. G., Emmert, J. T., Shepherd, G. G., and Solheim, B. H.: Average daytime $\mathrm{F}$ region disturbance neutral winds measured by UARS: Initial results, Geophys. Res. Lett., 27, 1859-1862, 2000.

Forbes, J. M., Gonzalez, R., Marcos, F. A., Revelle, D., and Parish, H.: Magnetic storm response of lower thermosphere density, J. Geophys. Res., 101, 2313-2319, 1996.

Fuller-Rowell, T. J., Codrescu, M. V., Rishbeth, H., Moffett, R. J., and Quegan, S.: On the seasonal response of the thermosphere and ionosphere to geomagnetic storms, J. Geophys. Res., 101, 2343-2353, 1996.

Goncharenko, L., Salah, J., Crowley, G., Paxton, L. J., Zhang, Y., Coster, A., Rideout, W., Huang, C., Zhang, S., Reinisch, B., and Taran, V.: Large variations in the thermosphere and ionosphere during minor geomagnetic disturbances in April 2002 and 
their association with IMF $B y$, J. Geophys. Res., 111, A03303, doi:10.1029/2004JA010683, 2006.

Ivanov-Kholodny, G. S. and Mikhailov, A. V.: The prediction of ionospheric conditions, Reidel, Dordrecht, 1986.

Mikhailov, A. V., Depueva, A. Kh., and Leschinskaya, T. Yu.: Morphology of quiet time F2-layer disturbances: High and lower latitudes, Int. J. Geomag. Aeronom., 1-14, GI1006, doi:10.1029/2003GI000058, 2004.

Mikhailov, A. V., Depuev, V. H., and Depueva, A. H.: Synchronous $N m \mathrm{~F} 2$ and $N m$ E daytime variations as a key to the mechanism of quiet-time F2-layer disturbances, Ann. Geophys., 25, 483-493, 2007 , http://www.ann-geophys.net/25/483/2007/.

Mikhailov, A. V. and Lilensten, J.: A revised method to extract thermospheric parameters from incoherent scatter observations, Ann. Geophys., Supp., 47, 985-1008, 2004.

Mikhailov, A. V. and Schlegel, K.: Self-consistent modeling of the daytime electron density profile in the ionospheric F-region, Ann. Geophys., 15, 314-326, 1997, http://www.ann-geophys.net/15/314/1997/.

Papagiannis, M. D., Hajeb-Hosseinien, H., and Mendillo, M.: Changes in the ionospheric profile and the Faraday factor M with $K_{p}$, Planet Space Sci., 23, 107-113, 1975.

Picone, J. M., Hedin, A. E., Drob, D. P., and Aikin, A. C.: NRLMSISE-00 empirical model of the atmosphere: Statistical comparison and scientific issues, J. Geophys. Res., 107, 1468, doi:10.1029/2002JA009430, 2002.
Prölss, G. W.: Magnetic storm associated perturbations of the upper atmosphere: recent results obtained by satellite-borne gas analyzers, Rev. Geophys. Space Phys., 18, 183-202, 1980.

Prölss, G. W.: Ionospheric F-region storms, Handbook of Atmospheric Electrodynamics, Vol. 2, edited by: Volland, H., CRC Press/Boca Raton, pp. 195-248, 1995.

Rishbeth, H.: How the thermospheric circulation affects the ionospheric F2-layer, J. Atmos. Solar-Terr. Phys., 60, 1385-1402, 1998.

Rishbeth, H. and Müller-Wodarg, I. C. F.: Vertical circulation and thermospheric composition: a modelling study, Ann. Geophys., 17, 794-805, 1999, http://www.ann-geophys.net/17/794/1999/.

Roosen, G. G.: The seasonal variation of geomagnetic disturbance amplitudes, Bull. Astron. Inst. Neth., 18, 295-305, 1966.

Shimazaki, T.: World-wide variations in the height of the maximum electron density of the ionospheric F2 layer, J. Radio Res. Labs. Japan, 2(7), 85-97, 1955.

Torr, M. R. and Torr, D. G.: The inclusion of a particle source of ionization in the ionospheric continuity equation, J. Atmos. Terr. Phys., 31, 611-615, 1969.

Zevakina, R. A.: Ionospheric disturbances, in: Ionospheric disturbances and their impact on radio communication, Science, Moscow (in Russian), pp. 3-26, 1971. 